\title{
Investigating the relationship between secreted protein acidic and rich in cysteine expression level and therapeutic efficacy of nab- paclitaxel: a meta-analysis
}

\author{
Xiaobo Zhou, Lan Zhang, Caihang Qierang, Min Huang, Xin Yang, Liangang Li, Jun Jiang \\ Department of Medical Oncology, Qinghai University Affiliated Hospital, Xining, China \\ Contributions: (I) Conception and design: J Jiang; (II) Administrative support: J Jiang; (III) Provision of study materials or patients: X Zhou, X Yang; (IV) \\ Collection and assembly of data: X Zhou, X Yang, C Qierang, M Huang, L Li; (V) Data analysis and interpretation: X Zhou, L Zhang, C Qierang; (VI) \\ Manuscript writing: All authors; (VII) Final approval of manuscript: All authors. \\ Correspondence to: Prof. Jun Jiang. Department of Medical Oncology, Qinghai University Affiliated Hospital, Xining 810000, China. \\ Email: xnrheum@126.com.
}

\begin{abstract}
Background: Secreted protein acidic and rich in cysteine (SPARC) is always considered as a marker of poor prognosis. However, it helps to transport nab-paclitaxel and may lead better therapeutic ending. This meta-analysis was aimed to assess the relationship between SPARC expression level and clinical efficacy of nab-paclitaxel.
\end{abstract}

Methods: The PubMed and Embase databases were searched from inception to April 2020, and search terms included nanoparticle albumin-bound paclitaxel, nab-paclitaxel, nab-PTX, Abraxane, ABI-007, secreted protein acidic and rich in cysteine, SPARC, osteonectin, and BM-40. In addition, funnel plots were used to indicate the existence of publication bias.

Results: After further screening the full text, 5 studies that involved 336 patients were finally included in the study, of which, 3 studies concentrated on non-small cell lung cancer (NSCLC) and the other 2 on breast cancer and pancreatic cancer. SPARC status in tumor cells and stromal cells was taken into account. The HR for progression-free survival (PFS) between SPARC high and low groups was 1.25 (95\% CI: 0.72-2.14, stromal cell) and 1.51 (95\% CI: 0.93-2.46, tumor cell). The HR for OS between SPARC high and low groups was 1.07 (95\% CI: 0.57-2.03, stromal cell) and 1.34 (95\% CI: 0.74-2.43, tumor cell). It was revealed that SPARC expression level in tumor cells or stromal cells was not significantly correlated with the patient's survival outcomes. No significant publication bias was found in each analysis.

Conclusions: SPARC expression level detected by immunohistochemistry (IHC) cannot predict the efficacy of nab-paclitaxel, while further large-scale clinical trials are required to confirm our findings.

Keywords: Secreted protein acidic and rich in cysteine; nanoparticle albumin-bound paclitaxel; chemotherapy; progression-free survival (PFS); overall survival (OS)

Submitted Oct 14, 2020. Accepted for publication Dec 12, 2020.

doi: $10.21037 /$ tcr-20-3045

View this article at: http://dx.doi.org/10.21037/tcr-20-3045

\section{Introduction}

Despite improvements in medical care, tumor remains the second leading cause of death worldwide (1). Combination of chemotherapy with cytotoxic drugs is a promising strategy for the treatment of several malignant tumors. Paclitaxel is a widely used antineoplastic agent that promotes assembly of microtubules, inhibits tubulin disassembly, and blocks cell cycling at the G2/M stage. Compared with the solvent-based paclitaxel, nanoparticle albumin-bound paclitaxel (nab-paclitaxel) does not require special infusion devices due to different paclitaxel carriers, without necessity of pre-treatment, associating with a lower 
incidence of adverse reactions and a higher degree of drug accumulation within the tumor, indicating its broad clinical applicability $(2,3)$.

Secreted protein acidic and rich in cysteine (SPARC), also known as osteonectin, is a bone-specific protein that binds selectively to both hydroxyapatite and collagen (4-6). It is secreted from several types of cancer and tumorassociated stroma cells, and can regulate tumor cell growth and metastasis (3,5,7-9). Studies demonstrated that even in the same type of cancer, a higher SPARC expression level predicts a worse prognosis (10-12). However, a recent meta-analysis found that although SPARC overexpression is an unfavorable prognostic factor in the majority of solid tumors, colon cancer patients with high SPARC expression level in stromal cells can benefit longer disease-free survival (DFS) (13).

Due to high dependence of SPARC to albumin, SPARC can deliver more drug particles to tumors through the unique gp60-caveolin-SPARC pathway (Figure 1), thereby causing remarkable anticancer effects (14-17). Besides, it was reported that nab-paclitaxel may be more effective in the treatment of tumors with high SPARC expression level (18). To date, a large number of clinical trials have employed SPARC to predict the efficacy of nab-paclitaxel, while no reliable and unified conclusion has been reached. To our knowledge, there is no meta-analysis specifically targeting the relationship between SPARC level and the efficacy of albumin-bound paclitaxel. Therefore, the present study aimed to investigate the relationship between SPARC expression level and clinical efficacy of nab-paclitaxel.

We present the following study in accordance with the PRISMA reporting checklist (available at http://dx.doi. org/10.21037/tcr-20-3045).

\section{Methods}

The Preferred Reporting Items for Systematic Reviews and Meta-Analyses (PRISMA) (19) statement was used to report this meta-analysis. Review Manager and Engauge Digitizer software were used for data extraction and analysis.

\section{Search strategy}

We used free-text words and MeSH terms to increase sensitivity. The PubMed and Embase databases were searched from inception to April 2020. The following search strategy was used on PubMed: ('nanoparticle albumin-bound paclitaxel' OR nab-paclitaxel OR nab-PTX
OR Abraxane OR ABI-007) AND ('secreted protein acidic and rich in cysteine' OR SPARC OR osteonectin OR BM40). On Embase database, we combined the search terms in pairs like (Abraxane AND SPARC) or (nab-paclitaxel AND osteonectin).

\section{Inclusion and exclusion criteria}

(I) The inclusion criteria were as follows: (i) studies published in English; (ii) utilizing at least one chemotherapy regimen containing nab-paclitaxel; (iii) measurement of SPARC expression level (regardless of the method or material) and evaluation of relationship between SPARC expression level and survival outcomes [progression-free survival (PFS) or overall survival (OS)].

(II) We adopted the following exclusion criteria: (i) studies published in form of reviews, editorial guidelines, or expert opinion letters; (ii) duplicate publication; (iii) application of only neoadjuvant therapy; (iv) studies that concentrated on only animal experiments.

\section{Data extraction and quality assessment}

Two authors (Xiaobo Zhou and Xin Yang) independently performed and reviewed the data extraction for the least selection bias. And the following data were extracted from the eligible studies: the full name of the authors, study design, patients' demographic and clinical characteristics, type of chemotherapy regimen, SPARC detection method, the type of antibody used for immunohistochemistry (IHC), SPARC positive expression, and patients' survival data (PFS or/and OS).

\section{Statistical analysis}

We used hazard ratio (HR) to evaluate the relationship between survival data and SPARC expression level. $\mathrm{HR}<1$ indicates that high SPARC expression level can result in superior survival benefits than low SPARC expression level. For those studies that did not directly present HR, HR was estimated based on the survival curves via data extraction using Engauge Digitizer 11.1 software (20). Since the majority of the included studies reported the relationship between SPARC expression level in tumor cells or stromal cells and patient's survival data, we calculated HR of both tumor cells and stromal cells. Xing et al. (21) demonstrated that the tumor tissues were only used for IHC. With assessment of previously reported images achieved by 


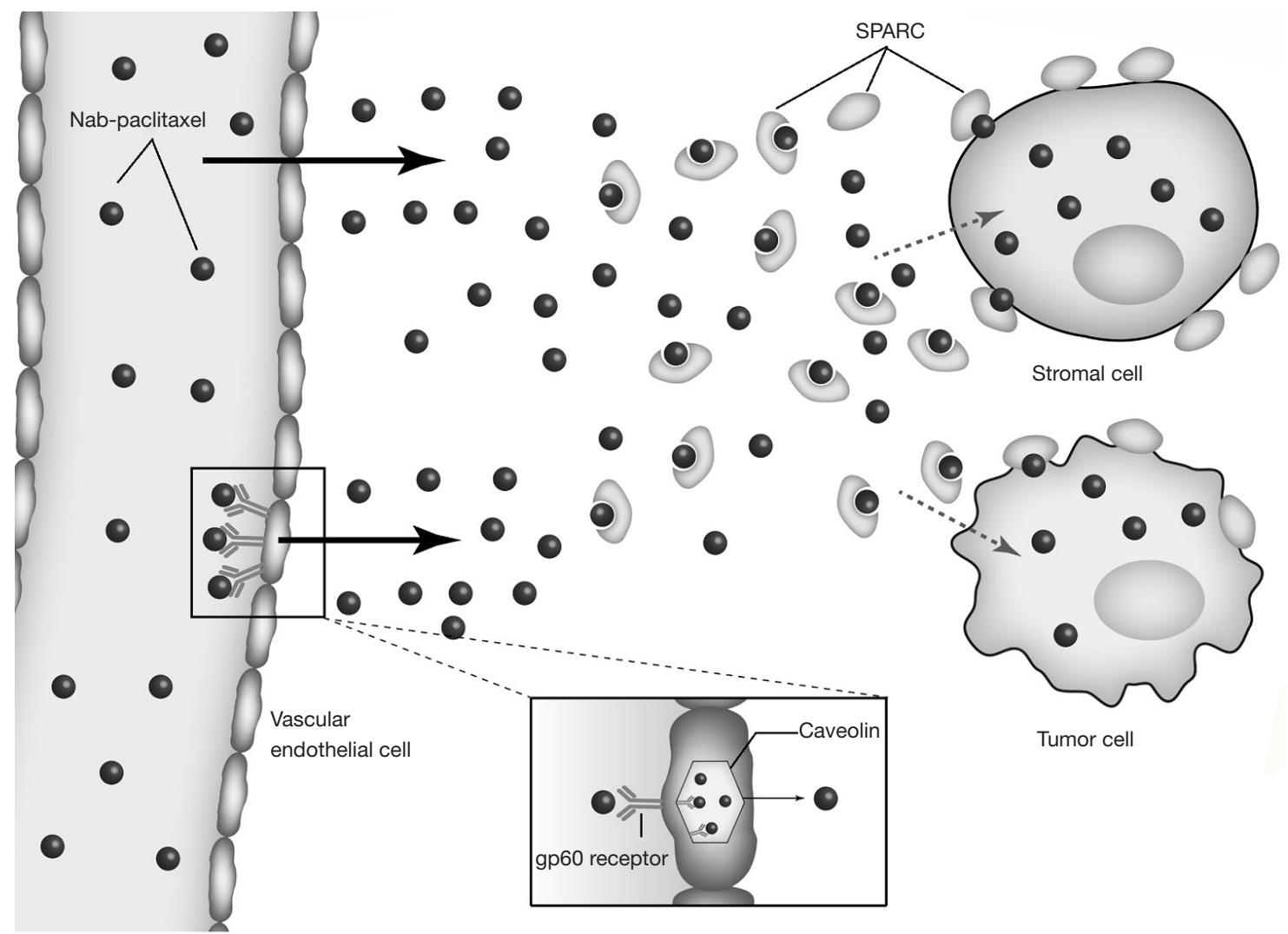

Figure 1 Transport mechanism of albumin-bound paclitaxel. SPARC, secreted protein acidic and rich in cysteine.

IHC, Xing et al.'s outcomes were included in our analysis. Heterogeneity between studies was evaluated by using the Cochran's Q-statistic test $(\mathrm{P}<0.05$ was considered statistically significant heterogeneity) and the inconsistency index $\mathrm{I}^{2}$ statistic $\left(\mathrm{I}^{2}>50 \%\right.$ was considered statistically significant heterogeneity). The fixed effects model by Mantel-Haenszel was used in the absence of between-study heterogeneity, and a random effects model by DerSimonian and the Laird would be used to investigate variation both from in-study and between-study. The significance of the pooled $\mathrm{HR}$ was determined by the $\mathrm{Z}$ test $(\mathrm{P}<0.05$ was considered significant).

\section{Quality control}

Because most of the studies that we included were singlearm or non-controlled studies, the Newcastle Ottawa Scale (NOS) was used to evaluate the quality of enrolled studies (22). Studies were divided into three grades: poor, modest, and high quality, according to scores ranging from $0-3,4-6$, and $7-9$, respectively.

\section{Results}

\section{Literature screening}

A total of 338 studies were included in the preliminary screening. Among them, 315 studies were excluded according to reading their title or abstract. After further screening the full text, 5 studies were finally included in the study, of which, 3 studies concentrated on non-small cell lung cancer (NSCLC) and the other 2 on breast cancer and pancreatic cancer. We created a flowchart to show the details of the inclusion process (Figure 2).

\section{Research features}

The main characteristics of the eligible studies are presented 


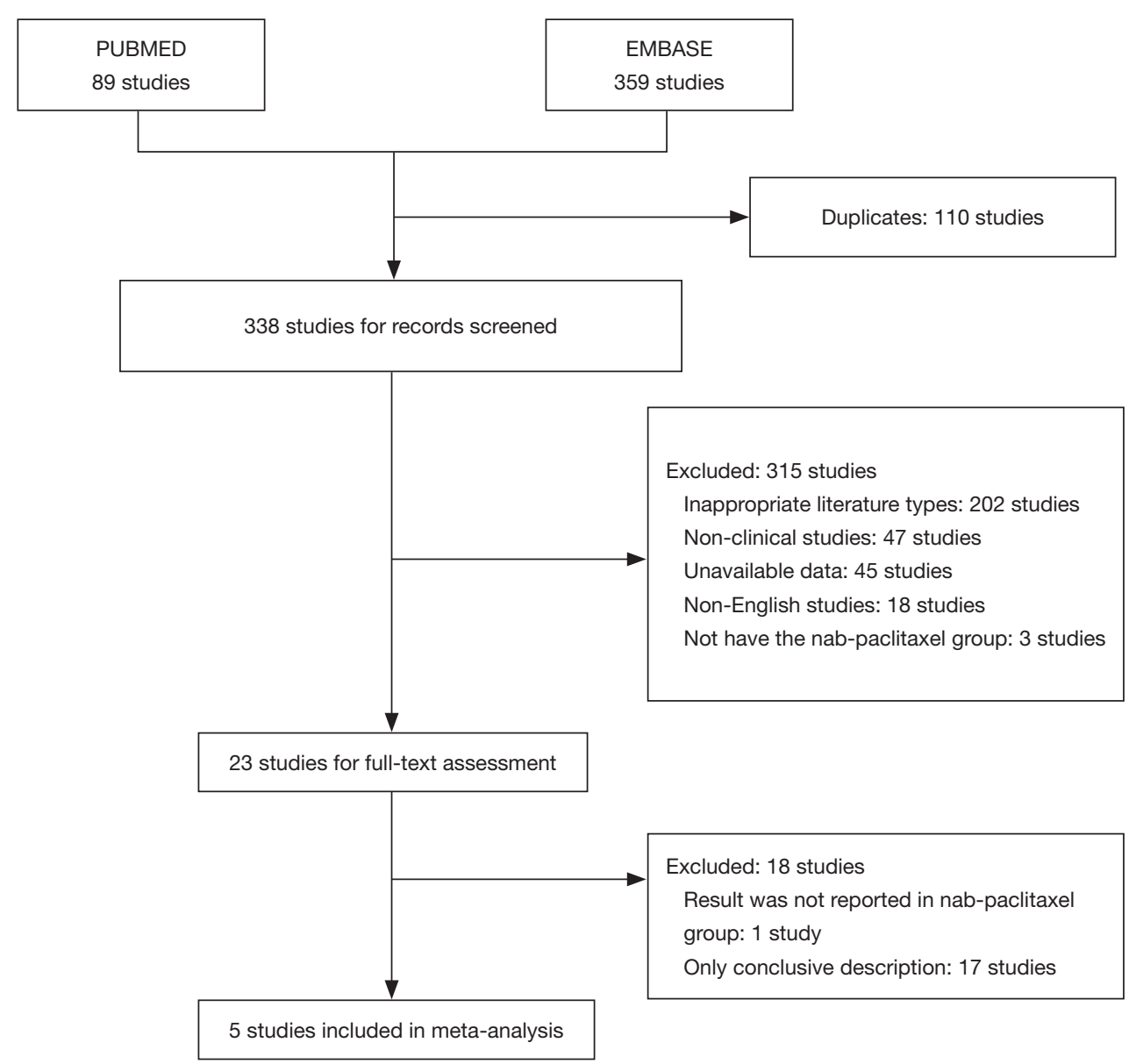

Figure 2 The flowchart of selection of studies.

in Tables 1-3. And the results of NOS were shown on Table 4. CI: 0.74-2.43, tumor cell).

\section{Meta-result}

Since no significant heterogeneity was found in each study group, we used the fixed effects model to combine HR and 95\% confidence interval (CI) through Review Manager 5.3 software.

The results showed that SPARC expression level in tumor cells or stromal cells (Figures 3 and 4) were not associated with the survival data (PFS or OS) of patients who were treated with nab-paclitaxel. The HR for PFS between SPARC high and low groups was 1.25 (95\% CI: 0.72-2.14, stromal cell) and 1.51 (95\% CI: 0.93-2.46, tumor cell). The HR for OS between SPARC high and low groups was 1.07 (95\% CI: 0.57-2.03, stromal cell) and 1.34 (95\%

\section{Sensitivity analysis}

Sensitivity analysis was performed to examine the potential impact of uncertain factors in this study. Removing any single study or using another effects model did not significantly alter our results, which indicates that the survival influences of SPARC level were still undetected when the potential study with a high risk of bias was omitted.

\section{Publication bias}

We did not evaluate the risk of publication bias by using any integrated testing tools, because the included studies were 
Table 1 The main characteristics of the eligible studies

\begin{tabular}{lllll}
\hline Study name & Number of patients & Tumor type & Type of chemotherapy regimen & Type of survival data \\
\hline Bertino et al., 2015 & 63 & NSCLC & Carboplatin plus nab-paclitaxel & PFS and OS \\
Duan et al., 2017 & 64 & NSCLC & Nab-paclitaxel & PFS and OS \\
Schneeweiss et al., 2014 & 44 & Brest cancer & Nab-paclitaxel & PFS and OS \\
Von Hoff et al., 2011 & 67 & Pancreatic cancer & Nab-paclitaxel & OS \\
Xing et al., 2017 & 98 & NSCLC & Nab-paclitaxel & PFS and OS \\
\hline
\end{tabular}

PFS, progression-free survival; OS, overall survival; NSCLC, non-small cell lung cancer.

Table 2 SPARC-related characteristics of the eligible studies

\begin{tabular}{|c|c|c|c|c|}
\hline Study name & Number of patients & Detection method & Antibody used for IHC & Positive expression \\
\hline Schneeweiss et al., 2014 & 37 & $\mathrm{IHC}(\mathrm{TC}+\mathrm{SC})$ & NCL-O-NECTIN, 1:100, Novocastra & $\begin{array}{l}\text { TC: } 5 / 37,14 \% \text {; SC: } 28 / 37 \text {, } \\
76 \%\end{array}$ \\
\hline Von Hoff et al., 2011 & 36 & $\mathrm{IHC}(\mathrm{TC})$ & 1:500; Abcam, Cambridge, UK & $19 / 36,53 \%$ \\
\hline Xing et al., 2017 & 24 & $\mathrm{IHC}(\mathrm{TT})$ & R\&D system, MAB941 & $7 / 24,29 \%$ \\
\hline
\end{tabular}

IHC, immunohistochemistry; TC, tumor cell; SC, stromal cell; TT, tumor tissue.

Table 3 Hazard ratios of each study

\begin{tabular}{|c|c|c|c|}
\hline Study name & $\mathrm{HR}$ (PFS), 95\% Cl & $\mathrm{HR}(\mathrm{OS}), 95 \% \mathrm{Cl}$ & HR source \\
\hline Duan et al., 2017 & SC: $2.71,0.83-8.82$ & SC: $1.05,0.37-2.95$ & Estimated \\
\hline Schneeweiss et al., 2014 & TC: $0.68,0.25-1.85 ;$ SC: $0.94,0.39-2.26$ & TC: $2.343,0.31-17.67 ;$ SC: $1.795,0.46-0.71$ & Original \\
\hline Von Hoff et al., 2011 & $\mathrm{~N} / \mathrm{A}$ & TC: $0.59,0.19-1.84$ & Estimated \\
\hline
\end{tabular}

$\mathrm{HR}$, hazard ratio; $\mathrm{Cl}$, confidence interval; PFS, progression-free survival; OS, overall survival.

Table 4 NOS score of each study

\begin{tabular}{|c|c|c|c|c|}
\hline Study name & \multicolumn{4}{|c|}{ NOS score } \\
\hline Bertino et al., 2015 & 4 & 1 & 2 & 7 \\
\hline Duan et al., 2017 & 3 & 1 & 2 & 6 \\
\hline Schneeweiss et al., 2014 & 4 & 2 & 2 & 8 \\
\hline Xing et al., 2017 & 3 & 1 & 2 & 6 \\
\hline
\end{tabular}



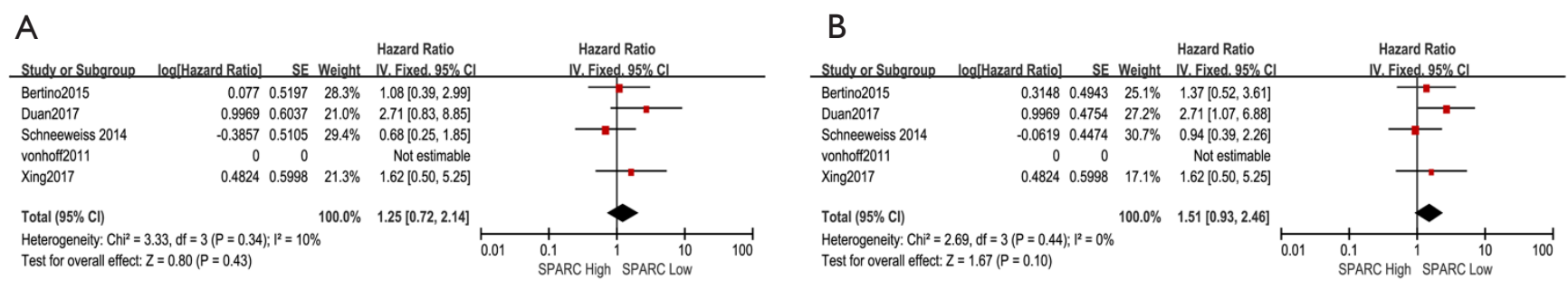

\section{C}
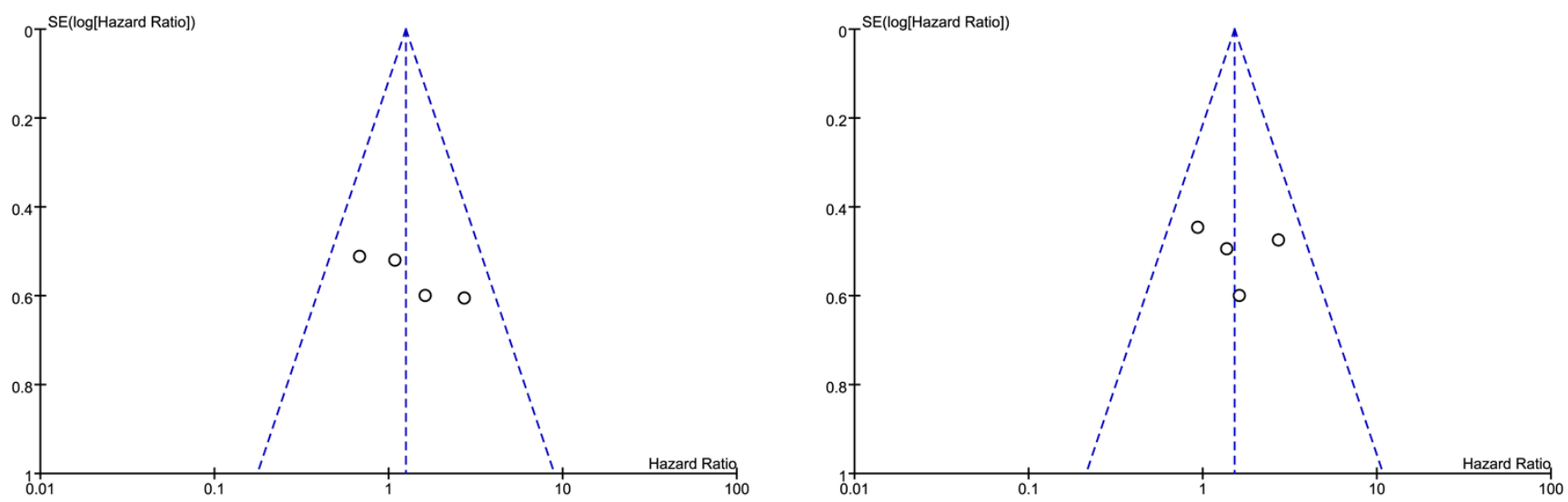

Figure 3 Investigation results of the relationship between SPARC expression level and PFS: (A) relationship between SPARC expression level in tumor cells and PFS; (B) relationship between SPARC expression level in stromal cells and PFS; (C) funnel plot of group A; (D) funnel plot of group B. SPARC, secreted protein acidic and rich in cysteine; PFS, progression-free survival.

neither randomized controlled trials nor non-randomized studies of interventions. Simultaneously, regarding the small number of studies included in our meta-analysis, conduction of a standard publication bias test was found inefficient. Therefore, we used funnel plots to indicate the existence of publication bias. And the results (Figures 3 and 4) did not show asymmetric images, indicating that there was no significant publication bias in the literature used in each analysis.

\section{Discussion}

The present meta-analysis, for the first time, indicated the predictive effect of SPARC expression level on the therapeutic efficacy of nab-paclitaxel. The results showed that there was no significant association between SPARC expression level and the therapeutic efficacy of nabpaclitaxel. It is noteworthy that 2 of 4 included studies $(23,24)$ indicated that the difference between SPARC expression level and patient's survival data was statistically significant. However, our findings revealed that even a high level of SPARC seemed to lead to a worse outcome (HR $>1$ in each group), there was no statistically significant difference between them. This may be due to the small sample size and the estimated HR. Since the survival curves were used to estimate the survival number in our study, and the survival curve represents the survival ratio, the number of survivors will remain stable for a long time because of the small study sample size. The above-mentioned findings indicated inconsistency between our findings and those reported previously. We attempted to increase the number of patients in the same proportion, and the results showed the same conclusion with no significant difference with the original literature, suggesting the importance of highquality, large sample size studies in the future.

According to previously conducted studies, SPARC contributes to tumorigenesis by promoting migration and epithelial-mesenchymal transition (EMT) of lung cancer cells (25). Therefore, it is almost regarded as a poor prognostic marker $(26,27)$ for patients with different 
A

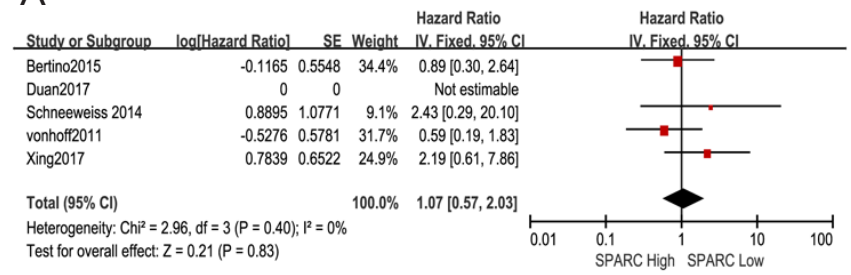

C

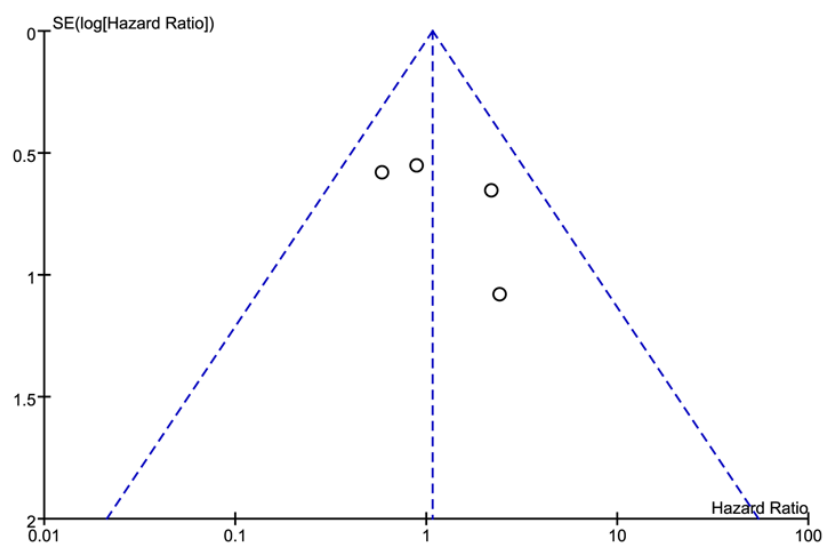

\section{B}

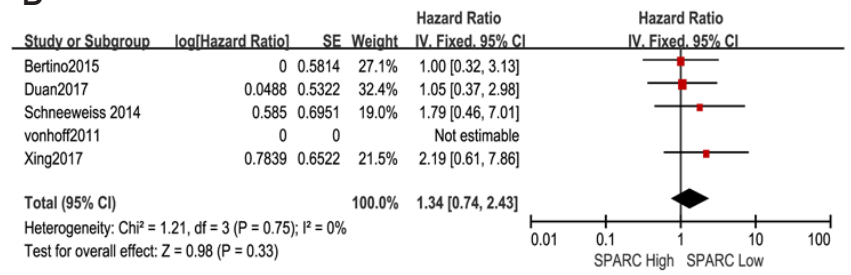

D



Figure 4 Investigation results of the relationship between SPARC expression level and OS: (A) relationship between SPARC expression level in tumor cells and OS; (B) relationship between SPARC expression level in stromal cells and OS; (C) funnel plot of group A; (D) funnel plot of group B. SPARC, secreted protein acidic and rich in cysteine; OS, overall survival.

types of cancer. Although nab-paclitaxel improves patient's survival compared with traditional taxanes $(28,29)$, the side effect of SPARC makes it a contradictory prognostic factor in treatment with albumin-bound paclitaxel. Although a number of studies demonstrated that SPARC overexpression indicates a higher pathologic complete response (pCR) rate in neoadjuvant therapy with nab-paclitaxel $(15,30)$, our study that included patients who received only systemic chemotherapy did not reveal any survival benefits with nab-paclitaxel. We will dynamically monitor the changes in SPARC expression levels with the treatment progress, which may be more significant to clarify the relationship between SPARC expression level and efficacy of nabpaclitaxel-related antitumor therapy.

Additionally, SPARC, as a secreted protein, not only exists in the cell surface, but also is discharged into the intercellular matrix and enters into the circulatory system. Giallongo et al. (31) investigated the variations in SPARC production by peripheral blood cells from chronic myeloid leukemia patients at the time of diagnosis and after treatment, and identified the subpopulation of cells that were the prevalent source of SPARC. We also included a study (32) that concluded efficacy of nab-paclitaxel in metastatic breast cancer does not associate with SPARC expression level in tumor tissues, while no statistical significant difference was noted in patients with higher plasma SPARC level and longer survival.

IHC was employed for the detection of SPARC expression level in all of the studies included in the current meta-analysis. Even in the 3 studies concentrating on NSCLC $(21,23,33)$, the difference in the proportion of SPARC positive expression was remarkable (29-57\%). We noticed that the reagents used in the IHC, as well as the scoring methods and cut-off values were also different, which may lead to differences in experimental results. The determination of the transcriptional mRNA level of SPARC may be more significant to evaluate SPARC expression level. Nakazawa et al. (14) confirmed the consistency between SPARC mRNA and protein levels. Although none of the studies included in the present meta-analysis 
had concentrated on SPARC mRNA level, in other nabpaclitaxel-based therapies, especially in neoadjuvant therapy, studies have shown that high SPARC mRNA level can often predict worse therapeutic effects $(14,34)$.

\section{Conclusions}

According to the results of the current meta-analysis, SPARC expression level in patients who were treated with nab-paclitaxel was not significantly associated with prognosis of such patients. As matters stand, SPARC is not a reliable biomarker to predict the prognosis of patients who were treated with nab-paclitaxel-related chemotherapy. However, the studies included in the current meta-analysis all had small sample sizes, were conducted in phase I/II and used IHC for detection. Therefore, further relevant prospective studies are required to confirm our findings. With the use of a standard method for detection of SPARC expression level, the accuracy of findings will be improved.

\section{Acknowledgments}

Funding: This study was supported by The Key Research \& Development and Transformation Project of Qinghai Province (Grant No. 2018-ZJ-T02) and Beijing Xisike Clinical Oncology Research Foundation (Grant No. Ysy2018-054). The funders had no role in study design, data collection and analysis, decision to publish, or preparation of the manuscript.

\section{Footnote}

Reporting Checklist: The authors have completed the PRISMA reporting checklist. Available at http://dx.doi.org/10.21037/ tcr-20-3045

Conflicts of Interest: All authors have completed the ICMJE uniform disclosure form (available at http://dx.doi. org/10.21037/tcr-20-3045). The authors have no conflicts of interest to declare.

Ethical Statement: The authors are accountable for all aspects of the work in ensuring that questions related to the accuracy or integrity of any part of the work are appropriately investigated and resolved.

Open Access Statement: This is an Open Access article distributed in accordance with the Creative Commons Attribution-NonCommercial-NoDerivs 4.0 International License (CC BY-NC-ND 4.0), which permits the noncommercial replication and distribution of the article with the strict proviso that no changes or edits are made and the original work is properly cited (including links to both the formal publication through the relevant DOI and the license). See: https://creativecommons.org/licenses/by-nc-nd/4.0/.

\section{References}

1. Naghavi M, Abajobir AA, Abbafati C, et al. Global, regional, and national age-sex specific mortality for 264 causes of death, 1980-2016: a systematic analysis for the Global Burden of Disease Study 2016. Lancet 2017;390:1151-210.

2. Pellegrino B, Boggiani D, Tommasi C, et al. Nabpaclitaxel after docetaxel hypersensitivity reaction: case report and literature review. Acta Biomed 2017;88:329-33.

3. Yardley DA. nab-Paclitaxel mechanisms of action and delivery. J Control Release 2013;170:365-72.

4. Wu XL, Tu Q, Faure G, et al. Diagnostic and Prognostic Value of Circulating Tumor Cells in Head and Neck Squamous Cell Carcinoma: a systematic review and metaanalysis. Sci Rep 2016;6:20210.

5. Mauzo SH, Milton DR, Prieto VG, et al. Summary of expression of SPARC protein in cutaneous vascular neoplasms and mimickers. Ann Diagn Pathol 2018;34:151-4.

6. Sangaletti S, Talarico G, Chiodoni C, et al. SPARC Is a New Myeloid-Derived Suppressor Cell Marker Licensing Suppressive Activities. Front Immunol 2019;10:1369.

7. Sun W, Feng J, Yi Q, et al. SPARC acts as a mediator of TGF-beta1 in promoting epithelial-to-mesenchymal transition in A549 and H1299 lung cancer cells. Biofactors 2018;44:453-64.

8. Lindner JL, Loibl S, Denkert C, et al. Expression of secreted protein acidic and rich in cysteine (SPARC) in breast cancer and response to neoadjuvant chemotherapy. Ann Oncol 2015;26:95-100.

9. Goyal S, Oak E, Luo J, et al. Minimal activity of nanoparticle albumin-bound (nab) paclitaxel in relapsed or refractory lymphomas: results of a phase-I study. Leuk Lymphoma 2018;59:357-62.

10. Zhu A, Yuan P, Du F, et al. SPARC overexpression in primary tumors correlates with disease recurrence and overall survival in patients with triple negative breast 
cancer. Oncotarget 2016;7:76628-34.

11. Li Z, Li AD, Xu L, et al. SPARC expression in gastric cancer predicts poor prognosis: Results from a clinical cohort, pooled analysis and GSEA assay. Oncotarget 2016;7:70211-22.

12. Vaz J, Ansari D, Sasor A, et al. SPARC: A Potential Prognostic and Therapeutic Target in Pancreatic Cancer. Pancreas 2015;44:1024-35.

13. Ma Y, Chen H, Ma H, et al. Prognostic role of secreted protein acidic and rich in cysteine in patients with solid tumors. Saudi Med J 2019;40:755-65.

14. Nakazawa Y, Nakazawa S, Kurozumi S, et al. The pathological complete response and secreted protein acidic and rich in cysteine expression in patients with breast cancer receiving neoadjuvant nab-paclitaxel chemotherapy. Oncol Lett 2020;19:2705-12.

15. Yang M, Qu H, Liu A, et al. Efficacy and safety of nanoparticle albumin-bound paclitaxel as neoadjuvant chemotherapy in HER2-negative breast cancer. J Cancer Res Ther 2019;15:1561-6.

16. Wei Y, Wang Y, Xia D, et al. Thermosensitive Liposomal Codelivery of HSA-Paclitaxel and HSA-Ellagic Acid Complexes for Enhanced Drug Perfusion and Efficacy Against Pancreatic Cancer. ACS Appl Mater Interfaces 2017;9:25138-51.

17. Desai N, Trieu V, Damascelli B, et al. SPARC Expression Correlates with Tumor Response to Albumin-Bound Paclitaxel in Head and Neck Cancer Patients. Transl Oncol 2009;2:59-64.

18. Komiya K, Nakamura T, Nakashima C, et al. SPARC is a possible predictive marker for albumin-bound paclitaxel in non-small-cell lung cancer. Onco Targets Ther 2016;9:6663-8.

19. Moher D, Liberati A, Tetzlaff J, et al. Preferred reporting items for systematic reviews and meta-analyses: the PRISMA statement. PLoS Med 2009;6:e1000097.

20. Tierney JF, Stewart LA, Ghersi D, et al. Practical methods for incorporating summary time-to-event data into metaanalysis. Trials 2007;8:16.

21. Xing P, Zhu Y, Shan L, et al. The role of weekly nanoparticle albumin bound paclitaxel monotherapy as second line or later treatment for advanced NSCLC in China. Oncotarget 2017;8:87442-54.

22. Lo CK, Mertz D, Loeb M. Newcastle-Ottawa Scale: comparing reviewers' to authors' assessments. BMC Med Res Methodol 2014;14:45.
23. Duan J, Hao Y, Wan R, et al. Efficacy and safety of weekly intravenous nanoparticle albumin-bound paclitaxel for non-small cell lung cancer patients who have failed at least two prior systemic treatments. Thorac Cancer 2017;8:138-46.

24. Von Hoff DD, Ramanathan RK, Borad MJ, et al. Gemcitabine plus nab-paclitaxel is an active regimen in patients with advanced pancreatic cancer: a phase I/II trial. J Clin Oncol 2011;29:4548-54.

25. Zhong ME, Chen Y, Xiao Y, et al. Serum extracellular vesicles contain SPARC and LRG1 as biomarkers of colon cancer and differ by tumour primary location. EBioMedicine 2019;50:211-23.

26. Hsiao YH, Lien HC, Hwa HL, et al. SPARC (osteonectin) in breast tumors of different histologic types and its role in the outcome of invasive ductal carcinoma. Breast J 2010;16:305-8.

27. Azim HA Jr, Singhal S, Ignatiadis M, et al. Association between SPARC mRNA expression, prognosis and response to neoadjuvant chemotherapy in early breast cancer: a pooled in-silico analysis. PLoS One 2013;8:e62451.

28. Zong Y, Wu J, Shen K. Nanoparticle albumin-bound paclitaxel as neoadjuvant chemotherapy of breast cancer: a systematic review and meta-analysis. Oncotarget 2017;8:17360-72.

29. O'Shaughnessy J, Gradishar WJ, Bhar P, et al. Nabpaclitaxel for first-line treatment of patients with metastatic breast cancer and poor prognostic factors: a retrospective analysis. Breast Cancer Res Treat 2013;138:829-37.

30. Martín M, Chacón JI, Antón A, et al. Neoadjuvant Therapy with Weekly Nanoparticle Albumin-Bound Paclitaxel for Luminal Early Breast Cancer Patients: Results from the NABRAX Study (GEICAM/2011-02), a Multicenter, Non-Randomized, Phase II Trial, with a Companion Biomarker Analysis. Oncologist 2017;22:1301-8.

31. Giallongo C, La Cava P, Tibullo D, et al. SPARC expression in CML is associated to imatinib treatment and to inhibition of leukemia cell proliferation. BMC Cancer 2013;13:60.

32. Schneeweiss A, Seitz J, Smetanay K, et al. Efficacy of nabpaclitaxel does not seem to be associated with SPARC expression in metastatic breast cancer. Anticancer Res 2014;34:6609-15.

33. Bertino EM, Williams TM, Nana-Sinkam SP, et al. 
Stromal Caveolin-1 Is Associated With Response and Survival in a Phase II Trial of nab-Paclitaxel With Carboplatin for Advanced NSCLC Patients. Clin Lung Cancer 2015;16:466-74.

Cite this article as: Zhou X, Zhang L, Qierang C, Huang M, Yang X, Li L, Jiang J. Investigating the relationship between secreted protein acidic and rich in cysteine expression level and therapeutic efficacy of nab-paclitaxel: a meta-analysis. Transl Cancer Res 2021;10(2):876-885. doi: 10.21037/tcr-20-3045
34. Nagayama A, Matsui A, Tachibana A, et al. Evaluation of neoadjuvant weekly nanoparticle albumin-bound paclitaxel for HER2-negative breast cancer. Ann Oncol 2016;27:vi68-vi99. 